\section{Lab. Psychopathology}

Experimental Psychopathology : Recent Research and Theory. Edited by H. D. Kimmel. Pp. xiii +264. (Academic: New York and London, December 1971.) $\$ 12.50 ; £ 5.85$.

FOR the greater part of its sixty-year history, experimental psychopathology, restricted here to studies of disorders of behaviour induced by deliberate manipulation of independent variables, has exerted little influence on psychiatry although it has contributed to the progressive shift of emphasis from genetical, biochemical and neurological explanations to explanations in terms of psychological processes. More recently its shortcomings in concept and method have been overcome in some degree, and this review of current research is timely, especially since it is introduced by reevaluations by Horsley Gantt and Jules Masserman of their pioneer work.

Pavlov regarded disorders as the accidental products of a brain whose functions had broken down through "overstrain" of excitatory or inhibitory processes, and did not try to explain them through analysis of the "difficult" conditions in which they had been shown to occur. The editor, restating Masserman's "uncertainty principle", points out that there are always two stages, the learning of adaptive patterns, and their confrontation with altered environmental demands which are uncertain, unpredictable or capricious. Disorders are the maladaptive consequences of adaptive behaviour. The question: "What is the special nature of the difficulties?" awaits a full answer.

The mixtures of symptoms which make up Pavlov's experimental neurosis have proved too complicated for study, and current researches focus on single aspects. Amsel, for instance, discusses the persistence, and Sandler and Davidson the extinction, of behaviour which is frustrated, that is, not rewarded when reward is anticipated. Persistence despite "pain" is the essence of Freud's neurotic paradox. The somatic concomitants of disorders of behaviour have assumed great importance, and Joseph Brady, known for his production of gastro-intestinal ulcers in "executive" monkeys, reviews, with Jack Findley, work on cardiovascular disorders, especially hypertension. The book ends with an account by Harry Harlow and his collaborators of the responses of infant rhesus monkeys to cloth and wire surrogate mothers.

One cause of its lack of influence on psychiatry is that experimental psychopathology has continued in the tradition of the psychological laboratory of studying the reactions of individuals to discrete environmental events. Psychiatry, on the other hand, has become increasingly concerned with social behaviour made up by sequences of interactions between persons. Harlow has prepared the way for the researches now being carried forward, perhaps notably by Robert Hinde in Cambridge, in which the surrogates have been replaced by natural mothers, and disordered patterns of interaction are systematically studied. The gap is being narrowed, but to intend a book for both scientists and clinicians seems unduly optimistic.

\section{Russell Davis}

\section{Fixing Nitrogen}

Biological Nitrogen Fixation. By J. Postgate. Pp. vi 61. (Merrow: Watford, 1972.) £1.25; \$4.

THIs small monograph by Dr Postgate is well written, concise and is easily read. He covers in a fairly complete way all of the current aspects of the fascinating problem of dinitrogen fixation. Anyone with a reasonable degree of biochemical knowledge should be able to read the book and follow it.

The book is organized in a logical manner. It uses tables and figures to good advantage. It starts out by describing the organisms or systems that fix dinitrogen and then goes into the most significant advances that have been made during the past ten years in the enzymology of the problem. Starting with the discovery of the first cell-free dinitrogen-fixing extracts, he leads one through the experiments that show the requirements for ATP, $\mathrm{Mg}$ and reduced ferredoxin and that demonstrate that two distinct protein components are needed. There is a discussion of the various substrates that are reduced by nitrogenase. The role of ATP and metal ions in $\mathrm{N}_{2}$ fixation is discussed and he points out clearly that present evidence is scanty,

The section on the physiology of $\mathrm{N}_{\text {, }}$ fixation discusses the role of oxygen, the nutritional requirements for organisms that fix $\mathrm{N}_{2}$, and the probable sources of electrons for $\mathrm{N}_{2}$ reduction. This section is followed by sections concerned with the control and regulation, ecology, evolution and chemistry of $\mathrm{N}_{3}$ fixation.

A few minor mistakes or omissions in references are made. The first demonstration that $\mathbf{H}_{2}$ and ATP supported nitrogen fixation was not by the cited authors. Kennedy, Jeng and Mortenson was the reference for the demonstration of $\mathrm{Mg}^{2}+$ requirement for nitrogenase and not Moustafa and Mortenson. Also the first referunces showing that ATP was required (McNary and Burris, J. Bacteriol., 84, 598; 1962; and Mortenson, Proc. US Nat. Acad. Sci., 52; 272; 1964) are not included.

Postgate's prediction in the preface has come true. Some items in the text have changed or are now no longer true.
One example is the effect of $\mathrm{CN}^{-}$on the Mössbauer spectrum of ${ }^{57} \mathrm{Fe} \mathrm{Kp}_{2}$. Further purification by that group has shown that the effect was the result of an impure preparation. But this does not significantly change the context of the book, since he stated that the results should be taken with caution.

In summary I feel this small book well worth reading. It is both informative and entertaining (from a scientific point of view). $\quad$ L. E. MORTENSON

\section{Soil Fungi}

Ecology of Soil Fungi. By D. M. Griffin. Pp. ix + 193. (Chapman and Hall: London, 1972.) $£ 2.80$.

Aт last a book has been published that can honestly be claimed a "must" for all who study soil ecology. The author, who never commits himself to paper unless he has something of significance to say, must be a delight to work with, albeit a stern taskmaster.

The book is in two parts. The first is a general study of factors such as the composition of the soil, fungal physiology and effects of other microorganisms, while the second discusses in detail the physical properties of the soil and their significance in the establishment and growth of soil fungi. A full mathematical treatment is given where possible.

The author is well aware of the difficulties of assessing quantitatively the complex interactions of the soil, soil microorganisms and the fungi. To do this with any degree of accuracy is extremely difficult. But the author points out pathways of research which can lead to the achievement of more precise results and therefore more significant theses. His descriptions of work done to assess the effects of various soil factors on the growth of fungi are always careful and precise. To me, the most important parts of this section are the warnings that laboratory conditions can never replicate exactly conditions in nature, and one must realize that what seems clearly established in the laboratory may not be so in the field. The author frequently demonstrates how detailed analyses have often un: covered remarkable differences between adjacent and superficially similar sites. I like the author's way of gently rebuking workers who have used assumptions as if they were established facts. One can be sure that when the author himself uses the word "probable", he is commenting from a wide range of research and experience, but needs more facts before he will say, "This is so".

Altogether this is a very useful and informative book. I look forward to another, when some of Dr Griffin's "probables" have been turned to certainties. MARGareT T. PotTs 